Yee Seng Tan and Edward R.T. Tiekink*

\title{
Crystal structure of catena-[( $\mu_{2}$-pyrazine- $\left.{ }^{2} N: N^{\prime}\right)$ - bis $\left(O, O^{\prime}\right.$-di-ethyldithiophosphato- $\left.{ }^{2} S, S^{\prime}\right)$ cadmium(II)], $\left\{\mathrm{C}_{12} \mathrm{H}_{24} \mathrm{CdN}_{2} \mathrm{O}_{4} \mathrm{P}_{2} \mathrm{~S}_{4}\right\}_{\mathrm{n}}$
}
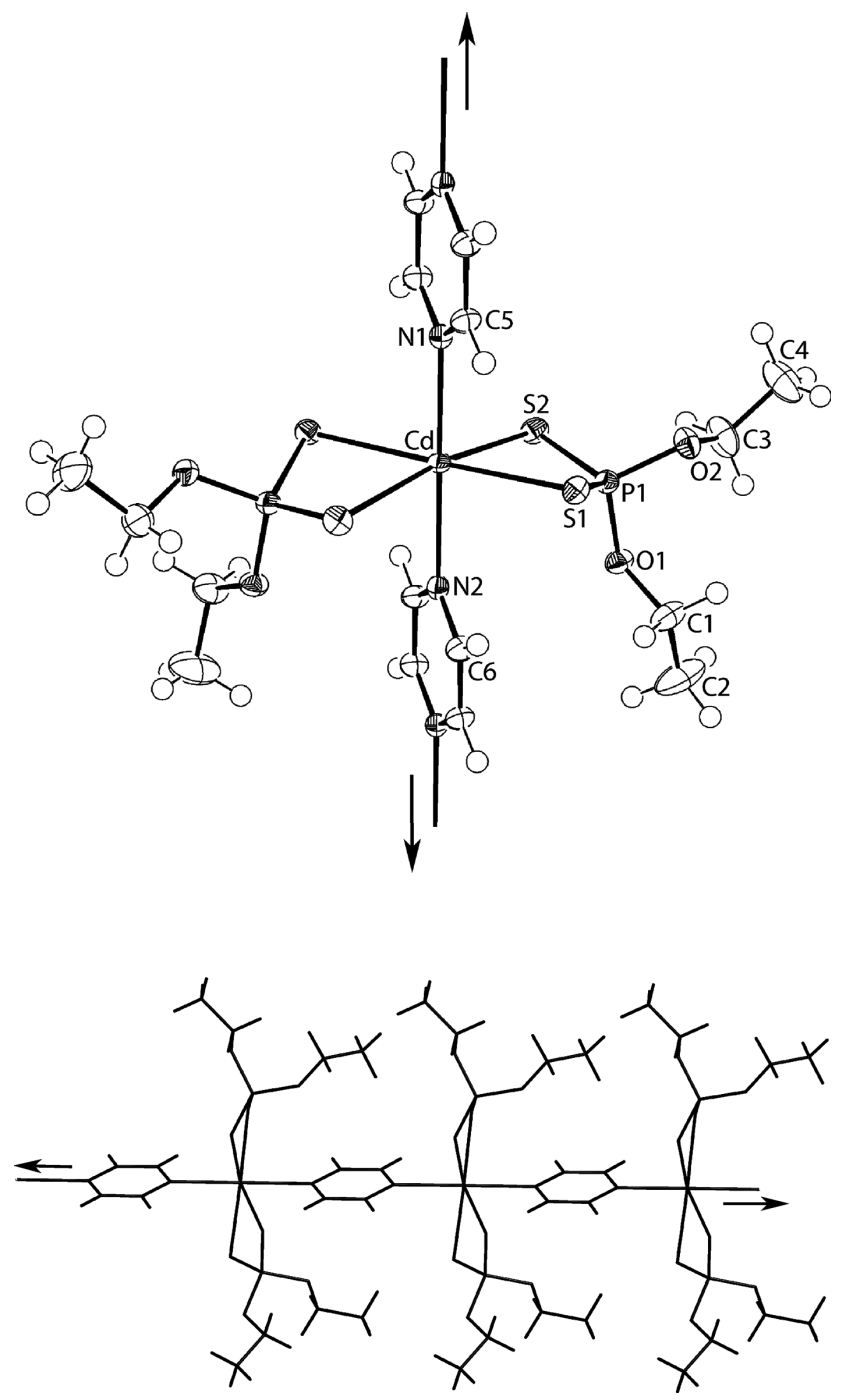

*Corresponding author: Edward R.T. Tiekink, Research Centre for Crystalline Materials, School of Science and Technology, Sunway University, 47500 Bandar Sunway, Selangor Darul Ehsan, Malaysia, e-mail: edwardt@sunway.edu.my. https://orcid.org/0000-00031401-1520

Yee Seng Tan: Research Centre for Crystalline Materials, School of Science and Technology, Sunway University, 47500 Bandar Sunway, Selangor Darul Ehsan, Malaysia

๑ Open Access. ( 2019 Yee Seng Tan et al., published by De Gruyter. (cc)BY License.

https://doi.org/10.1515/ncrs-2019-0648

Received September 3, 2019; accepted October 16, 2019; available online November 6, 2019

\begin{abstract}
$\mathrm{C}_{12} \mathrm{H}_{24} \mathrm{CdN}_{2} \mathrm{O}_{4} \mathrm{P}_{2} \mathrm{~S}_{4}$, monoclinic, $P 2 / n \quad$ (no. 13), $a=11.7844(2) \AA, \quad b=7.6063(1) \AA, \quad c=13.1965(2) \AA$, $\beta=111.594(2)^{\circ}, \quad V=1099.86(3) \AA^{3}, \quad Z=2, \quad R_{\mathrm{gt}}(F)=0.0171$, $w R_{\text {ref }}\left(F^{2}\right)=0.0467, T=100 \mathrm{~K}$.
\end{abstract}

CCDC no.: 1959640

Table 1 contains crystallographic data and Table 2 contains the list of the atoms including atomic coordinates and displacement parameters.

Table 1: Data collection and handling.

Crystal:

Size:

Wavelength:

$\mu$ :

Diffractometer, scan mode:

$\theta_{\max }$, completeness:

$N(h k l)_{\text {measured }}, N(h k l)_{\text {unique }}, R_{\text {int }}$ :

Criterion for $l_{\text {obs }}, N(h k l)_{\text {gt }}$ :

$N(\text { param })_{\text {refined }}$ :

Programs:

\author{
Yellow prism \\ $0.21 \times 0.11 \times 0.08 \mathrm{~mm}$ \\ Cu $K \alpha$ radiation (1.54184 ̊̊) \\ $13.1 \mathrm{~mm}^{-1}$ \\ XtaLAB Synergy, $\omega$ \\ $67.1^{\circ},>99 \%$ \\ $12357,1960,0.021$ \\ $I_{\text {obs }}>2 \sigma\left(I_{\text {obs }}\right), 1949$ \\ 117 \\ CrysAlis $^{\text {PRO }}[1]$, SHELX [2, 3], \\ WinGX/ORTEP [4]
}

\section{Source of material}

The $\mathrm{Cd}\left[\mathrm{S}_{2} \mathrm{P}(\mathrm{OEt})_{2}\right]_{2}$ precursor was prepared in high yield from the in situ reaction of $\mathrm{Cd}\left(\mathrm{NO}_{3}\right)_{2} \cdot 4 \mathrm{H}_{2} \mathrm{O}$ (Acros Organics; $15.42 \mathrm{~g}, 0.05 \mathrm{~mol}$ ), EtOH (Merck; $12.25 \mathrm{~mL}, 0.21 \mathrm{~mol}$ ), $\mathrm{P}_{2} \mathrm{~S}_{5}$ (Sigma-Aldrich; $11.11 \mathrm{~g}, 0.05 \mathrm{~mol}$ ) and 50\% w/w NaOH solution (Merck; $8.80 \mathrm{~mL}, 0.11 \mathrm{~mol}$ ). The title compound was obtained by mixing a suspension of $\mathrm{Cd}\left[\mathrm{S}_{2} \mathrm{P}(\mathrm{OEt})_{2}\right]_{2}(0.50 \mathrm{~g}$, $1.04 \mathrm{mmol}$ ), pyrazine (Merck, $0.09 \mathrm{~g}, 1.12 \mathrm{mmol}$ ) in dimethylformamide (Merck; $5 \mathrm{~mL}$ ), followed by stirring for $30 \mathrm{~min}$. at $373 \mathrm{~K}$. The solution was filtered, the filtrate was dissolved in acetonitrile (Merck; $1 \mathrm{~mL}$ ) and held in a sample vial. Yellow crystals formed after one day. Yield: $0.15 \mathrm{~g}$, (25.6\%, based on $\mathrm{Cd}\left[\mathrm{S}_{2} \mathrm{P}(\mathrm{OEt})_{2}\right]_{2}$ ). M.pt (MelTemp Melting Point Apparatus): 430.2-432.2 K. IR (Bruker Vertex $70 \mathrm{~V}$ equipped 
Table 2: Fractional atomic coordinates and isotropic or equivalent isotropic displacement parameters $\left(\AA^{2}\right)$.

\begin{tabular}{lrrrr}
\hline Atom & $\boldsymbol{x}$ & $\boldsymbol{y}$ & $\boldsymbol{z}$ & $\boldsymbol{U}_{\text {iso }} \boldsymbol{U}_{\text {eq }}$ \\
\hline Cd & 0.250000 & $0.26705(2)$ & 0.250000 & $0.01170(7)$ \\
S1 & $0.13015(4)$ & $0.26199(5)$ & $0.03434(4)$ & $0.01404(11)$ \\
S2 & $0.43145(4)$ & $0.29672(6)$ & $0.17353(4)$ & $0.01542(11)$ \\
P1 & $0.29145(4)$ & $0.34260(6)$ & $0.03540(3)$ & $0.01227(11)$ \\
O1 & $0.29205(11)$ & $0.54937(16)$ & $0.01490(10)$ & $0.0155(3)$ \\
O2 & $0.30864(13)$ & $0.25480(16)$ & $-0.06730(12)$ & $0.0171(3)$ \\
N1 & 0.250000 & $-0.0465(3)$ & 0.250000 & $0.0126(4)$ \\
N2 & 0.250000 & $0.5876(3)$ & 0.250000 & $0.0125(4)$ \\
C1 & $0.19491(18)$ & $0.6268(3)$ & $-0.07831(16)$ & $0.0233(4)$ \\
H1A & 0.116764 & 0.624213 & -0.066364 & $0.028^{*}$ \\
H1B & 0.184606 & 0.559572 & -0.145355 & $0.028^{*}$ \\
C2 & $0.2302(2)$ & $0.8126(3)$ & $-0.0898(2)$ & $0.0410(6)$ \\
H2A & 0.164203 & 0.870026 & -0.149096 & $0.062^{*}$ \\
H2B & 0.304792 & 0.813320 & -0.106268 & $0.062^{*}$ \\
H2C & 0.244762 & 0.876071 & -0.021527 & $0.062^{*}$ \\
C3 & $0.4168(2)$ & $0.3048(3)$ & $-0.09081(18)$ & $0.0272(5)$ \\
H3A & 0.489242 & 0.309613 & -0.022284 & $0.033^{*}$ \\
H3B & 0.404677 & 0.422576 & -0.125074 & $0.033^{*}$ \\
C4 & $0.4361(2)$ & $0.1723(3)$ & $-0.1658(2)$ & $0.0351(5)$ \\
H4A & 0.508071 & 0.204600 & -0.182105 & $0.053^{*}$ \\
H4B & 0.364245 & 0.168743 & -0.233558 & $0.053^{*}$ \\
H4C & 0.448756 & 0.056297 & -0.131073 & $0.053^{*}$ \\
C5 & $0.15206(16)$ & $-0.1384(2)$ & $0.18873(14)$ & $0.0148(4)$ \\
H5 & 0.081034 & -0.077428 & 0.143738 & $0.018^{*}$ \\
C6 & $0.15177(16)$ & $0.6792(2)$ & $0.18933(14)$ & $0.0150(4)$ \\
H6 & 0.080141 & 0.618175 & 0.145637 & $0.018^{*}$ \\
\hline & & & &
\end{tabular}

with Platinum ATR): 1160(w) v(C-0); 1009(s) v(P-0); 665(m) $v(\mathrm{P}-\mathrm{S})$.

\section{Experimental details}

The $\mathrm{C}$-bound $\mathrm{H}$ atoms were geometrically placed $(\mathrm{C}-$ $\mathrm{H}=0.95-0.99 \AA)$ and refined as riding with $U_{\text {iso }}(\mathrm{H})=1.2-$ $1.5 U_{\text {eq }}(\mathrm{C})$.

\section{Comment}

A recent review of the structural chemistry of the zinctriad 1,1-dithiolates [e.g. dithiocarbamate $\left({ }^{-} \mathrm{S}_{2} \mathrm{CNR}_{2}\right)$, xanthates $\left({ }^{-} \mathrm{S}_{2} \mathrm{COR}\right)$ and dithiophosphates $\left.\left({ }^{-} \mathrm{S}_{2} \mathrm{P}(\mathrm{OR})_{2}\right)\right]$ with bipyridyl-type ligands, revealed relatively few examples of structures featuring the simplest of all potentially bridging ligands of this class of molecule, namely pyrazine (pyr) [5]. For dithiocarbamates, two examples are known, i.e. binuclear $\left\{\mathrm{Zn}\left[\mathrm{S}_{2} \mathrm{CN}\left(\mathrm{CH}_{2} \mathrm{CH}_{2} \mathrm{OH}\right)_{2}\right]_{2}\right\}_{2}$ (pyr), isolated in solvent-free form and as a dioxane solvate [6]. A sole example of a zinc(II) xanthate adduct is known, i.e. a linear coordination polymer $\left[\mathrm{Zn}\left(\mathrm{S}_{2} \mathrm{COEt}\right)_{2}(\mathrm{pyr})\right]_{\mathrm{n}}$ [7]. Similarly, there is only one dithiophosphate example, again with zinc(II), namely $\left\{\mathrm{Zn}\left[\mathrm{S}_{2} \mathrm{P}(\mathrm{O}-\mathrm{iPr})_{2}\right]_{2}\right\}_{2}$ (pyr), i.e. binuclear [8]. In the absence of structural data for cadmium analogues, herein the crystal and molecular structures of $\left\{\mathrm{Cd}\left[\mathrm{S}_{2} \mathrm{P}(\mathrm{OEt})_{2}\right]_{2}(\mathrm{pyr})\right\}_{\mathrm{n}}$, (I), are described in continuation of long-held interest in this area $[5,9]$.

The immediate coordination geometry about the cadmium atom is illustrated in the figure $(70 \%$ probability displacement ellipsoids). The cadmium(II) lies on a crystallographic 2-fold axis with the second dithiophosphate ligand related by the symmetry operation (i) $1 / 2-x, y, 1 / 2-z$. The 2-fold axis bisects the pyrazine molecule with the N1 and N2 atoms lying on the axis (the remaining atoms for each residue shown in the figure are generated by translation, i.e. for the N1-pyrazine molecule, (ii) $x, 1+y, z$ and for the N2-pyrazine, (iii) $x,-1+y, z)$. The cadmium(II) centre is octahedrally coordinated within a trans $-\mathrm{N}_{2} \mathrm{~S}_{4}$ donor set defined by two chelating dithiophosphate ligands and two pyrazine-nitrogen atoms. The $\mathrm{Cd}-\mathrm{S} 1[2.6715(5) \AA]$ and $\mathrm{Cd}-\mathrm{S} 2[2.6889(4) \AA]$ bond lengths differ by only $0.017 \AA$ and this symmetric mode of coordination is reflected in the near equivalence of the P1-S1 [1.9924(6) $\AA$ ] and P1-S2 [1.9881(6)] bond lengths. There are two independent $\mathrm{Cd}-\mathrm{N}$ bond lengths, i.e. $\mathrm{Cd}-\mathrm{N} 1$ [2.385(2) $\mathrm{A}]$ and $\mathrm{Cd}-\mathrm{N} 2[2.438(2) \AA]$, and these are experimentally distinct. A noteworthy feature of the structure is the relative disposition of the dithiophosphate ligands. Often, these are co-planar in bipyridyl-type adducts of cadmium dithiophosphates [5]. However, in the present case, these are twisted as seen in the dihedral angle between the two $\mathrm{CdS}_{2}$ residues of 10.366(17) ${ }^{\circ}$.

The lower view of the figure highlights the extended onedimensional coordination polymer which, from symmetry, is strictly linear and aligned along the $b$-axis direction. A linear coordination polymer was also noted in $\left[\mathrm{Zn}\left(\mathrm{S}_{2} \mathrm{COEt}\right)_{2}(\mathrm{pyr})\right]_{\mathrm{n}}$ [7]. The common feature of both the preceding structures is a trans $-\mathrm{N}_{2} \mathrm{~S}_{4}$ donor set about the central metal atom. However, in an accompanying report [10], a cis- $\mathrm{N}_{2} \mathrm{~S}_{4}$ donor set is found in the crystal of $\left\{\mathrm{Cd}\left[\mathrm{S}_{2} \mathrm{P}(\mathrm{O}-\mathrm{iPr})_{2}\right]_{2}(\mathrm{pyr})\right\}_{\mathrm{n}}$, isolated as a diacetonitrile solvate, with the result that the one-dimensional coordination polymer formed has a zig-zag topology [10].

In the crystal, the chains pack without directional interactions between them based on the criteria assumed in PLATON [11].

Acknowledgements: Sunway University Sdn Bhd is thanked for financial support of this work through Grant no. STRRCTR-RCCM-001-2019.

\section{References}

1. Rigaku Oxford Diffraction: CrysAlis ${ }^{\mathrm{PRO}}$. Rigaku Corporation, Oxford, UK (2018).

2. Sheldrick, G. M.: A short history of SHELX. Acta Crystallogr. A64 (2008) 112-122.

3. Sheldrick, G. M.: Crystal structure refinement with SHELXL. Acta Crystallogr. C71 (2015) 3-8. 
4. Farrugia, L. J.: WinGX and ORTEP for Windows: an update. J. Appl. Crystallogr. 45 (2012) 849-854.

5. Tiekink, E. R. T.: Perplexing coordination behaviour of potentially bridging bipyridyl-type ligands in the coordination chemistry of zinc and cadmium 1,1-dithiolate compounds. Crystals 8 (2018) 18.

6. Jotani, M. M.; Poplaukhin, P.; Arman, H. D.; Tiekink, E. R. T.: Supramolecular association in ( $\mu_{2}$-pyrazine)-tetrakis $(N, N$-bis (2-hydroxyethyl)dithiocarbamato)dizinc(II) and its di-dioxane solvate. Z. Kristallogr. CM 232 (2017) 287-298.

7. Ara, I.; El Bahij, F.; Lachkar, M.: Synthesis, characterization and X-ray crystal structures of new ethylxanthato complexes of zinc(II) with $\mathrm{N}$-donor ligands. Synth. React. Inorg. Met.-Org. Nano-Met. Chem. 36 (2006) 399-406.
8. Chen, D.; Lai, C. S.; Tiekink, E. R. T.: Supramolecular aggregation in diimine adducts of zinc(II) dithiophosphates: controlling the formation of monomeric, dimeric, polymeric (zig-zag and helical), and 2-D motifs. CrystEngComm 8 (2006) 51-58.

9. Lai, C. S.; Tiekink, E. R. T.: Engineering polymers with variable topology - bipyridine adducts of cadmium dithiophosphates. CrystEngComm 6 (2004) 593-605.

10. Tan, Y. S.; Tiekink, E. R. T.: Crystal structure of catena-poly $\left[\left(\mu_{2}\right.\right.$-pyrazine- $\left.N, N^{\prime}\right)$-bis $\left(O, O^{\prime}\right.$-diisopropyldithiophosphato-S, $\left.S^{\prime}\right)$ cadmium(II) acetonitrile disolvate], $\left[\mathrm{C}_{16} \mathrm{H}_{32} \mathrm{CdN}_{2} \mathrm{O}_{4} \mathrm{P}_{2} \mathrm{~S}_{4} \cdot 2\left(\mathrm{C}_{2} \mathrm{H}_{3} \mathrm{~N}\right)\right]_{\text {n. Z }}$. Kristallogr. NCS 235 (2020) 323-325.

11. Spek, A. L.: Structure validation in chemical crystallography. Acta Crystallogr. D65 (2009) 148-155. 